\title{
Article \\ Other Ways of Knowing: The Intersection of Education when Researching Family Roots
}

\author{
Diana Hart \\ Center for Leadership Studies and Research, School of Professional Studies, University of Phoenix, \\ Tempe, AZ 85282, USA; diana.hart24@gmail.com; Tel.: +1-440-538-9470
}

Received: 9 March 2018; Accepted: 29 April 2018; Published: 7 May 2018

\begin{abstract}
The intersection of education and genealogy is of interest to academia. Although learning is an important aspect of the genealogist's need to understand the connection with family relationships, there is a paucity of research about the intersection between education and genealogy. This study sought to answer the research question, "How do genealogists use education to better understand family connections?" A narrative inquiry method was used to interview 10 members of the Oberlin African-American Genealogy and History Group, in Oberlin, Ohio (OAAGHG). Participants were recruited through convenience sampling and purposive sampling, after an announcement about the study was presented at the January meeting of the genealogy society. Members who were interested in participating contacted the researcher through e-mails, text messages, and by telephone. Interviews were transcribed, and transcripts were sent to each member to verify the accuracy of each transcript. Nvivo11 was used to assist with analysis of the data. The results of the study presented three ways that education intersected with genealogy: self-directed learning, collaborative learning, and life-long learning. The conclusion of this study is that genealogists are life-long learners and expand their education as necessary to better understand family connections.
\end{abstract}

Keywords: education; learning; family genealogy; genealogy and education; family communication; self-directed learning; collaborative learning; lifelong learning, narrative inquiry

\section{Introduction}

Genealogy research is a life-long learning pursuit for those engaged in researching their family roots (Darby and Clough 2013; Fulton 2009; Hershkovitz and Hardof-Jaffe 2017). There are many twists and turns that present obstacles or dead ends along the way and many researchers find that they must find ways around those dead ends when possible. Individuals who pursue the work involved in genealogy research find that they are learning more than just family information. In fact, to identify some issues about their families and tell their stories, they must study a variety of topics that can include geography, history, foreign language, map reading, topography, and more in order to gain a sense of how family members may have lived. In this respect, the study of genealogy becomes a multi-disciplinary learning opportunity for those who continually engage in the process (Hershkovitz 2012). These topics thrust the amateur genealogist into academic areas that many are surprised to find as they continue to dig deeper into their family histories (Fulton 2016; Hershkovitz 2012).

Genealogy is both personal and private; however, the research brings a wealth of understanding about life in general, whether it is past or present, and opens a chance for deeper knowing of the self as it relates to the world (Bottero 2015; Darby and Clough 2013; Fulton 2016). Genealogy has become more important to people who are searching for a sense of belonging (Ball 2016; Bottero 2015). Genealogists become committed to leaving no piece of information unknown, which motivates them to explore a variety of areas such as birth and death records, cemeteries, 
libraries, historical societies and conferences to continuously find more information to tell the story of their ancestors (Duckworth et al. 2007; Fulton 2016; Hackstaff 2009).

Most genealogists who participated in this study had some college education; however, they did not see how their academic pursuits may have influenced their tenacity in studying their family histories. A discussion of alternative ways of learning that did not include the classroom suggested that the pursuit of genealogy, although academic in many ways, was not seen as a formal means of education. Instead, the pursuit of genealogy brought a variety of opportunities for learning that were not originally thought about when the genealogists began their research (Hackstaff 2009; Kramer 2011; Scodari 2016; Smith 2017).

\subsection{Literature Review}

The term genealogy is often used in a variety of ways to mean different things. I found this out as I began to do research into how genealogy and education intersected. At first, using keywords such as family histories, family history, genealogy, genealogists, and education, I found several articles unrelated to the study of genealogy. Both Imperato and Imperato (2009) and Olry and Haines (2003) noted that family histories were important to understanding the chronology of disease from the beginning to how it exists in the present. I continued to use keywords like family history, historical memory, race, memory, autobiography and genealogy, kinship, ethology, clans, kin, imaginary social world, and symbolic ancestors. Each of these provided more information about genealogy, but not specifically about how education intersected with genealogy or how genealogy used education. The various topics I found in the literature are stated in the literature review.

\subsubsection{Medicine and Family Histories}

In medicine, family history relates to a family's history of disease or the history of a disease. Although these topics were not relevant to my particular study, it was interesting that the word genealogy was used in this way. The literature about education and genealogy is scarce, although there are articles related to the study of family research and genealogy. Also, I found that different fields such as medicine, communications, sociology, cultural studies and others use the term genealogy to mean a chronology or history of a disease or medical family history.

\subsubsection{What Genealogists Do}

I narrowed the topic down to include only the terms genealogy and education and found a few articles that provided information on what genealogists do and broke down different parts of the genealogist's methods. Perusing these articles provided an in-depth look of how genealogists attempt to make sense out of their family histories. For example, Ball (2016) stated that the important aspect of family research is to identify the stories of family members to be shared with others. Ball also suggests that there are limitations to genealogy research, which can include gaining information from family members that may not be totally true or not having a true sense of the timeline of the history. One of the ways that genealogists use this information is to find the truth of the story. Darby and Clough (2013) had a slightly different perspective on genealogists in studying the behavior that transpired as research was conducted. Genealogists go through specific stages as they search for information, as depicted by the conceptual model created by the authors. Genealogy literature is also a subset of sociology and anthropology. For example, Kramer (2011) studied genealogy from both of these disciplines and saw that genealogy relates to kinship, identity, and affinity. In fact, the idea of kinship can be used to map affinities to connectedness, relatedness, and self-identity.

Gatson (2003) studied the difficulties that arise as genealogists work with their family histories. Sometimes these families are accurate and sometimes they are not. The genealogist's task is to sort the reality from the fiction in family stories. Several participants told stories they heard that were not based in truth. Sometimes when truth was revealed, family members who had kept the information secret for years would deny the truth when it was revealed. 
Genealogy was also reviewed by individuals who used it as a way to spark interest in other education topics. For example, Friday (2014) noted that genealogists have certain behaviors during research that send them into a pursuit of academic subjects. Participants talked about how they found more interest in history, math, reading, and other subjects because of what they were finding in their research. Sleeter (2008) studied teachers who taught multicultural studies and showed how a teacher's own multicultural experience could be used to become better teachers of multicultural studies.

\subsubsection{Information Seeking}

Another important aspect of the genealogist's work is to gather information. Information-gathering is an aspect of any type of educational pursuit, especially when writing papers. Fulton $(2009,2016)$ presented a series of articles about how important information seeking is to genealogists. Fulton found that genealogists are a unique group of people who seek information about their family histories and take a great deal of pleasure in finding the information. This information was consistent with the participants in this study because finding information was part of the fun of doing genealogy. Yakel (2004) also delved into how genealogists use libraries and archival information to further their knowledge of family histories. The interesting aspect of this article was that Yakel noticed from her interviews that genealogists do not have a specific end goal in mind.

Banville (2014) talked about different types of genealogists and how each played a part in the process of finding out about family roots. In addition, Banville suggested that finding a connection to our families can strengthen a sense of belonging. Several participants spoke about how doing genealogy and finding the truth about ancestors built their self-esteem. Parham (2008) noted that people gather ideas through their experiences in race, identity, and inequality. As Parham noted, when people have a connection to a specific ethnic group, "it provides a great deal of meaning" (p. 16). Parham also notes that many African Americans use genealogy and history as a way to "make sense of what it means to be black" (p. 16).

Lambert (2006) stated that it was important to record ancestral information accurately and that knowledge of national and local history helped adults compose stories that can help them better understand how their ancestors may have lived. This information was essential to the participants in this study because the need to find ancestral information that was accurate about their link to a specific ethnic group or groups was noted by all participants.

Freund and Toms (2016) added that historians and genealogists have different ways of finding information but that, working together, they gain more references. Several participants related the fact that they worked with historians or were attracted to becoming historians for the sake of providing information to others.

\subsubsection{Archival Information and Cataloguing}

Many participants talked about using archival information and, in the literature, working with different types of information and cataloging this information was important. The literature showed how genealogists and catalogers could work together. For example, in Long's (Long 2016) article he pointed out that many genealogical resources could be useful to catalogers because most genealogists have information on cultural groups, business organizations, and occupational records that may be useful to catalogers. Archival information is important to genealogists, which is one of the reasons that several participants said that going to the library instead of online was important. Duff and Johnson (2002) showed the different approaches that historians use to find information. This article showed four approaches (orientation toward the archives, finding resources, seeking the material that is known, and identifying relevant information) historians use as they are moving toward the information needed.

Genealogists in the study also talked about the various ways that they found specific information that fit into Duff and Johnson's approaches. A point made by Redmann (1993) discussed how archivists and genealogists could work together, and also presented the fact that, in the past, genealogy was 
not seen as an academic field. Also, genealogists were not taken seriously because, in the beginning, many genealogists were only concentrating on connecting themselves to famous people and did not concentrate on historical research. However, this may not be true of genealogists now because many-in this study) concentrate on areas of historical information and become experts in those fields.

\subsubsection{Genealogy as It Relates to Education}

I was looking for articles related to how genealogy was related to education and found only a few. Hershkovitz $(2012,2016)$ agrees there is a need for more articles in this area. In Hershkovitz (2012) the author presents the idea that a community needs to be built to help genealogy become more meaningful as an academic discipline and provides ideas of how this may be accomplished. Hershkovitz presents a taxonomy with six components that could be used to present this process. Hershkovitz (2016) explores the idea of education as an academic discipline and provides the work of several scholars who are a part of a special issue on the topic. An interesting note in this article is how many scholars use their own genealogy research to segue into their various disciplines. Hershkovitz and Hardof-Jaffe (2017) took the idea of genealogy as a multi-disciplinary process for life-long learning, which is also an aspect of the current study. The genealogists that I interviewed had continued their research over the course of several years.

Although, for many genealogists, the search for family roots begins as a hobby, the process for others becomes a life-long pursuit as the individual becomes more involved with learning about family and more adept at research (Duckworth et al. 2007; Fulton 2009; Kramer 2011). Family members also want to pass on their information to other family members. New topics can also emerge that could include historical challenges like slavery and early Native American education, the various wars, conservation, architecture, and European customs-all of these categories came to light in this research as participants related their stories. In addition, the deeper individuals go into the search for their roots, the more education may become a part of their discoveries. By reading broadly about the topic of genealogy and reflecting on the meaning of all of this information, I wanted to gain a better understanding of how genealogists used education.

\subsubsection{Traveling for Genealogical Purposes}

Ray and McCain (2009) studied the motivations that people use for researching genealogy, especially as it relates to travel to the ancestral home during vacations. All participants talked about planning vacations around specific places where their ancestors lived. This was a surprise to me because I never realized that people would actually find houses where their ancestors lived that were still standing. Also, Santos and Yan (2009) suggested that the ability to visit an ancestral home was important to the self-esteem of genealogists and to their connection to the ancestors. Many participants shared stories of tracking down ancestral homes just to gain an understanding of how the ancestor lived in a specific period of time. Stein (2009) researched Holocaust survivors who began searching their family histories to explain their identities; this seems to be a common aspect of genealogy. Many survivors had to visit concentration camps to create meaning. One participant spoke about going to her ancestor's plantation house (a bed and breakfast now) to walk through the different rooms to get a sense of what it was like for her ancestors.

\subsection{Summary}

There are a variety of issues that can be discussed and written about under genealogy and this literature review presented several categories that genealogists explore. There is limited information about how education and genealogy intersects, which can be an area for future educators and genealogists to consider as they continue research. This literature review serves as a way to understand many different aspects of genealogy as it relates to other subjects. 


\section{Materials and Methods}

This article will present interviews from 10 participants who found that as they engaged in researching their roots, alternative ways of learning surfaced as they found different ways of knowing about their families. All of this information became a part of the genealogists' toolbox as each learned to be an investigator or detective finding obscure information. Each found that becoming an active genealogist also meant that there are more opportunities for learning and teaching than was previously thought (Hackstaff 2009; Kramer 2011; Scodari 2016; Smith 2017).

To gain a better understanding of the research topic, the research question that developed was, "How do genealogists use education to better understand family connections?" It is hoped that this research will add to the field of education and genealogy and how they intersect, as there is a paucity of this information currently in the literature (Hershkovitz 2012, 2016). The conclusions that this article presents are that learning through the study of genealogy is self-directed, collaborative, and presents an opportunity for life-long learning.

A narrative inquiry method was used because I was interested in the stories of individuals. I started my own genealogy several years ago, although I had not realized that so much information was available or open to the public. I wanted to create an analytical study of genealogy as it intersects with education. As Birchall (2014) noted, narrative inquiry allows the researcher to "explore meaning, interpretations and individual experiences" (p. 1). By using the stories of individual participants, Cooper and Hughes (2015) stated that individuals are able to identify and create a sense of self-hood. Hickson (2016) noted that critical reflection adds to narrative inquiry and provides a way for participants to explore their own stories and this deepens an understanding of a central idea. To me, genealogy is about finding the truth (or not) of family stories and learning how these stories are interpreted.

\subsection{Recruitment Process}

The recruitment process began when I contacted a person I met at a special event and she agreed to make an announcement about the study at the next meeting, which was in January 2018. The announcement included details about the study, the fact that participant information would be kept confidential, why the group was being chosen, and my contact information (both e-mail address and telephone number). Although several participants mentioned interest, they did not follow up at first. I asked my contact to ask for phone numbers and e-mails of possible participants. She forwarded them to me and I called potential participants, explained the study, and asked them individually to participant. During the first phone call, we set a time for the interview. Although I stated initially that the interviews would be from $45 \mathrm{~min}$ to an hour, most interviews were two to three hours once participants began to answer questions. The only criterion for the study was that participants had been active in genealogy research for at least a year. There were no criteria relating to gender, age, or specific types of genealogy research. Participants gave verbal approval for participating and each chose a time that was convenient to be interviewed. Due to unpredictable weather conditions, all interviews were conducted via telephone.

There are approximately 50 members in the Oberlin African American Genealogy and History Group, the group that was chosen for the study. The group was founded in 2001 and became a non-profit in 2002. This group has monthly meetings and special events. Special events offer extra genealogy help, well-known speakers, and other topics that are relevant to genealogy. Members of the group provide a drop-in program at the public library where anyone can drop in during specific hours and receive help to do family research. The group provides assistance at the local high school during the school year and teaches students how to do genealogy research. This group was chosen because I was introduced to some members when I attended one of their special events in 2017.

Ten participants were interviewed, ranging in age from 49 to 79 . Nine women and one man answered 10 interview questions. The characteristics of the group are shown in Table 1. A time convenient for the participant was set for each interview. Interviews began with short demographic 
questions and then moved on to the main questions. Some of the questions were: "Tell me about your interest in genealogy-how did you get started, why did you start, any interesting tidbits you want to share about the beginning." "What was your process from the beginning? Where did you go, what questions did you ask?" "What skills did you have when you started? What skills have you developed?" The first few questions were asked to build rapport and to gain an understanding of how the participants evolved from being hobbyists to more active genealogists. I asked questions that I felt would show the evolution of participants from beginning to end. I wanted to be able to extrapolate the ways in which genealogists used education to further their work. Table 1 provides demographic information on the participants.

Table 1. Participant characteristics.

\begin{tabular}{cccccc}
\hline Code & Male/Female & Age & Race/Ethnicity & Level of Education & $\begin{array}{c}\text { Experience in } \\
\text { Genealogy Research } \\
\text { (Number of Years) }\end{array}$ \\
\hline G1 & F & 69 & AA & BA degree & 17 \\
G2 & F & 49 & AA & Some college & 10 \\
G3 & M & 73 & C & BA degree & 18 \\
G4 & F & 62 & C & BS degree & 20 \\
G5 & F & 61 & AA & some college & 5 \\
G6 & F & 75 & AA & almost doctorate & 16 \\
G7 & F & 67 & AA & some college & 10 \\
G8 & F & 79 & Mixed & some college & 20 \\
G9 & F & 68 & AA & some college & 30 \\
G10 & F & AA & master's degree & 1 \\
\hline Key: & African American \\
AA & Caucasian \\
C & (See Appendix B for list of all interview questions). \\
Mixed & Several ethnicities together
\end{tabular}

\section{Participant Descriptions}

The 10 participants lived in Oberlin or neighboring communities in Lorain County. Each participant had been doing family research for at least a year. Participant G1 is a librarian who works at a local public library and holds a bachelor's degree. Participant G1 keeps a journal to organize her research so she has something to refer back to as she goes along. She began with her husband's family, who are Puerto Rican, and she has introduced her children to the family in Puerto Rico and has introduced both families to each other. She was introduced to genealogy by another OAAGHG. She only had computer skills when she began research. Participant G2 worked at a local college and started genealogy in earnest when she was approached to come to a meeting of the OAAGHG. She became very adept at finding resources and helping others. She had limited skills when she began and the members of the group helped identify other resources. Participant G3 was the only male that was interviewed. He is a retired history teacher who taught at the high school. He attributes some of his interest in genealogy to his love of history; genealogy made history more real. He started because of the TV series Roots and he is adept at finding free resources.

Participant G4 has an accounting degree and was always interested in numbers and math. She found out that her husband had both Norwegian and German lineage, which led to them learning Finnish to read some of the records of information. She found that there are differences in how records are kept in America and other countries. She also found that the house she lived in has a rich history and started researching the history of the house, which made her "a white woman researching black history." She said she got strange looks in the beginning until people got to know the purpose of her research and got to know her. Participant G5 had some college and became interested in finding out 
more about her family because she discovered she had three great-aunts she knew nothing about. She began by collecting photos and putting names to the photos, then talking to her older family members to see what they knew. Participant G6 finished her education to her doctorate but did not finish her dissertation. She has thought about going back to school, but genealogy has fulfilled her need for education. Her interest in education heightened after she retired from a local high school. She was attending family reunions and meeting people she did not know or did not know how they fit into the family.

Participant G7 began her family search nine years ago by going online and searching for free genealogy resources. Because she had computer skills, she thought this was a good place to begin. She started by finding as much information as she could about her family. She had an insatiable curiosity about where her people came from and how this related to her own life. Participant G8 found that she had a number of nationalities that made her who she is, beginning with Native American. Other parts of her heritage are Bermudian, Scottish, Irish, and Welce. She is an activist for indigenous people and has dedicated a lot of her life to helping her Native American tribe. She created a specific format to follow in the beginning, which insured that she would become known for having accurate records. She has spoken to many groups about her specific genealogy.

Participant G9 became interested in genealogy when Alex Haley came to Oberlin College on a stop on his book tour for Roots. She went to his lecture, which made her more curious about her family. She enrolled in a free winter term project that took students to the National Archives in Washington, DC. She started with her grandmother because she was named after her and wanted to know more about her namesake. Participant G10 has a master's degree and was interested in getting started with her family history several years ago, but did not really become interested until her mother started pointing out people around her home town or when she was at a family reunion who were part of the family. She would approach these people and they would look at her with ion. She decided to find out more about the family and how people were related to each other.

\subsection{Data Collection}

Participants were chosen through two non-probability sampling methods: purposive and convenience sampling. These methods are similar in that the researcher makes a decision about who to contact (purposive sampling) and the sample is convenient to the researcher (convenient sampling). Yin (2012) suggested that the goal of purposive sampling is to find participants who will provide the most relevant and sufficient data. In convenience sampling, the selection of data stems from a network of individuals who are readily available (Etikan et al. 2016).

To understand the narratives of each individual, it was necessary to allow participants to describe their experiences freely without judgement. Birchall (2014) noted that participants tend to discuss feelings and that feelings are not necessarily based in fact. In genealogy, participants are passionate about finding the truth of their ancestors and understanding what may have happened to them, how it happened, where they lived, etc. Critics of narratives want to downplay investigations such as this; however, when discussing family history, participants provided a richness of descriptions to tell their stories. Each participant stated that a particular event sparked an interest to know more. For example, Participant G6 stated:

I just feel into it. It was absolutely perfect for me. So, I didn't know how these people fit in and had a little curiosity about it ... it was like opening a door a crack to see a little and then flinging the door open all the way. (Female, 75)

One or two interviews were conducted each day over the phone. A conversational style of interviewing was used to assist with building rapport. I began by asking questions about when they started studying their family histories, why they started, whether they had formal education or not, and what ethnicity they considered themselves. For a full list of interview questions, see Appendix B. 
I am adept at taking notes and copying each word, over the phone, as people tell their stories. I asked participants to stop periodically during the call, to make sure I had every word. Once all interviews were completed, I created transcripts in Word and loaded these into Nvivo11. Transcripts were then sent to participants to ensure accuracy. All participants were given four days to read over their transcript, change or add anything, and return them; participants had the option to approve the transcript "as is" by not returning the transcript with corrections or just letting me know they had no changes. Participants were identified with a code to preserve anonymity. For example, participant G1 means that this was the first genealogy interview. The participants requested that the name of the organization be used for this study and this is why it is included. Interviews were done between 14 and 24 January 2018.

\subsection{Data Analysis}

To find common themes, preliminary analysis was done by reading each transcript twice, and highlighting certain words or phrases that appeared. Once transcripts were returned, I read through each one again. My next step was to load the transcripts into Nvivo11 (pro edition). Nvivo11 is a software program created to "organize, analyze, and find insights in unstructured, or qualitative data" (QSR International 2017, para. 3). NVivo is often used by researchers to work with qualitative data and back up findings with evidence (QSR International 2017). I used Nvivo11 to organize the data and create nodes (themes) and relationships within the nodes. Specifically, I used the following steps in Nvivo11 to analyze the data:

1. Identified relevant information pertaining to the research question.

2. Assigned words and phrases that best represented the relevant information.

3. Create nodes to suggest relevant themes from the words and phrases. Also created word trees, looking for any connections to words or phrases I might have missed (see Appendix A for an example of a word tree).

4. I used auto coding, a feature available in Nvivo11, to look at individual pieces of information.

5. I did word queries using the keywords "education," "genealogy," "genealogy and education" to see how these words and phrases intersected with one another.

6. From the word trees and nodes, themes began to emerge. Preliminary themes were self-directed learning, collaborative learning, life-long learning, beginning and learned skills, importance of conferences, presentations, helping others, other opportunities, organization of research, changes in self, topics researched because of genealogy, vacations, slavery, and spiritual journey.

After these six steps, I examined my notes on themes and explored relationships between the nodes with one of the Nvivo11 tools. I found that all the themes could be reduced to three to answer the research question, "How do genealogists use education to better understand family connections?" The three most prevalent themes that emerged were self-directed learning, collaborative learning, and life-long learning. All protocols for working with human subjects, listed in the Belmont Report, were followed. I also have an updated CITI certification.

\section{Results}

The results of the study showed that adults in this study who conduct genealogy research continue to learn past a degree. The learning creates a link to their ancestors and promotes a stronger sense of belonging. As participants in the study described their journey, the learning progression was quickly related to specific issues that came up as the participants continued to do research. Also, interests changed. For example, several participants talked about reading novels that were based on historical fact. It seemed that as participants researched, they became more engrossed in history and other topics. 
Participants stated that they began studying genealogy because of an event in their lives. Such events included the death of an elder, going to a family reunion where a relative showed up and no one knew who they were, or finding pictures of people who were said to be family members but the pictures were not labeled. One participant stated that Alex Haley came to town on his book tour and this sparked interest.

Scodari (2016) stated that the study of family history creates empathy for family situations that may not have been totally positive. As Smith (2017) suggested, both positive and negative information will be found that can affect family relationships. Participant G3 said this about his family: "I learned that no family is perfect and that families are complicated; people don't want to talk about things; found out some family members have lived interesting lives" (Male, 73).

Genealogy became a way for families to tell their own unique stories, find the truth to stories that have been passed down from one generation to the next, and gain a sense of how each family member fits into the larger group. Smith (2017) found that "using a blend of family narratives, artifacts, and experiences, families work to shape both individual and family identities" (p. 2).

Through the telling of their stories, each participant in this study provided rich and vivid descriptions of what they found to be true or not true within their families. One very important story was about finding the name of an ancestor on a Bill of Sale and on a slaveholder's will. Two participants related this experience. In learning this type of information, participants experienced a mixture of emotions. When asked how this felt, participant G6 gave a very vivid description:

It was a most profound experience. Very painful. Especially painful was the settlement of the estate and their increase. The increase were the children of the female slave. This family all had to be divided between the [slaveholder's] five grandchildren. I thought about what she [the ancestor] must have felt like seeing her children being separated from her and never to be seen again. But freeing them would have been like giving away wealth for the slaveholder. I tear up every time I talk about it. (Female, 75)

Slavery is not something that is experienced by all African Americans. There were many blacks that were born free and some blacks owned slaves (Bottero 2015; Burr 2016; Dorsey 2009; Pressly 2006). This is one of the many surprises that some participants found as they continued the research.

Family members have stories that they hope they can find more information about as they research. Researching stories that family members have related, or finding bits of information that were at first thought to be irrelevant to the research, can spark a change within the individual. For example, two African-American participants stated that they were not interested in researching the White sides of their families. However, "you have to research White people because you can't get to black people without following White people. Whites may be neighbors, slaveholders, employers or business owners" (participant G1).

This was for some a difficult situation when they realized that their ancestors were attached to people who were not family members.

\subsection{The Connection between Genealogy and Learning: Three Phases}

Genealogy and education connect on several different levels. With each level, a different type or amount of information is gained, according to participants in this project. Participants described three phases that can happen step-by-step, simultaneously, or within certain amounts of time. As participants described their learning, it was clear that learning happened in three different ways: self-directed, collaborative learning, and life-long learning.

\subsection{Phase 1: Self-Directed Learning}

For participants in the study, genealogy began with curiosity about an unknown family member who may appear at a family reunion, in a picture, or because of an artifact that was passed down through generations. These preliminary interactions sparked a need to know more. All participants in 
the study stated they felt they were in the roles of detective or investigator, and became the storytellers for their families. Ball (2016) noted that it is common for genealogists to take on these roles and added that they may take on the role of historian as well. Often, the individuals have limited skills and must find information on their own. This first phase can be called self-directed learning.

In the self-directed phase of research on families, the amateur genealogist comes to the research with limited skills. All participants were asked the question, "what skills did you have when you first started?" The experience they had ranged from no experience to computer skills, research skills, or a knowledge of history or other topics. Participants also saw their skills as "the ability to read and write" (Participant G5: Female, 61), "good computer skills," (Participant G2: Female, 49), or the individual might just "like doing puzzles" (Participant G4: Female, 62). Participant G1 listed another level of skills:

I already had research skills from my undergrad experience, the gift of gab, a strong curiosity. Those skills pushed me to find the answers to the increasing number of questions that popped up [like]: Could that be the same family? (Female, 69)

Another participant, G3, who retired from teaching high school, stated, "I have a background in history. I had an advantage and I knew resources or had resources that others didn't have" (Male, 73).

All participants said they had computer skills in the beginning that allowed them to begin research at the library. Participants began with Ancestry.com because it is a well-known site and the library has a subscription to the service. Five participants stated they came with research skills. All participants came to genealogy research with one year of college or more; five had a degree (see Table 1). Two participants stated they always liked research, so research on the family came easily.

Obviously, research for these participants is important and is focused on specific topics. Asbury (2017) noted that historical research is the foundation of educational practice. All 10 participants stated that some skills were enhanced, while others were learned out of necessity. Participant G6 stated, "I think my skills are more intense, more exhaustive than before. I learned to dig deeper, work slower, and with more insight." All participants knew how to use the library, but the study of genealogy influenced the types of libraries they used and the information they needed from repositories, genealogy societies, cemetery records, etc. There is so much to learn to add to skills already obtained. Participant G2 stated:

Not just libraries but utilizing heritage centers and finding out where they are, what they use and knowing how to find those records at local references. Takes a skill to know what rock to actually look under. Another skill I know I developed was through [a] oral history project and learning how to work with a transcription program and didn't have that skill before. Also, how to conduct oral history interviews. (Female, 49)

As interest grew, the concept of digging deeper meant that participants would have to gain more knowledge because, without this new knowledge, they were at a dead end in the research. This gaining of new knowledge happened as a natural progression as they gained answers to questions. Each question that was resolved opened up new questions. Although one participant stated that the computer was their only means of research, nine participants said they needed to go beyond the computer because computers had limited information. Sometimes participants planned vacations to destinations where they could also do genealogy research. This could be out of state, to a different county or region because "you may find information they don't tell you about and you'll find it on your own. I look in a lot of history books from [different] counties and these books will have the family name in it" (Participant G9: Female, 68).

Hackstaff (2009) stated that some genealogists are obsessed with the research and sometimes this obsession caused problems with other family members who do not share their interest. This was not true for these participants. All shared their information with other family members, although all stated that their children were not yet interested. Participants want to find younger family members to teach 
so that they can preserve what has already been done. Nine participants stated that, although they try to get other family members involved, their family members do not have the same level of interest. Stokas (2015) stated that genealogy requires certain levels of grit, defined as "working strenuously toward challenges, maintaining effort and interest over years despite adversity and plateaus in progress" (p. 513). All participants showed examples of grit as they acknowledged an obsession with the research, especially as they dug deeper, because the more they researched, the more there was to find.

Six participants related stories of how the increase in information, learning new skills, and developing an expertise in genealogy research transformed their thinking in some way or made them look at the world differently. Nerstrom (2017) stated that some genealogy research can unsettle family members or cause challenges. This new information can be transformational and present a new or fresh perspective. As participants researched, there were surprises along the way that created a change within them. For example, one participant stated, "I have a civil war diary that is very well preserved and I have transcribed and sent copies to sons and relatives." The diary is an account of what his ancestor did on a day-to-day basis while in the war.

All participants stated that finding one or two items in preliminary research made something change within them. Shy participants found they became more outgoing as a result of learning more. Participants also stated that education in certain areas was enhanced. Participants who hated math or history found that they loved both when these subjects related to their specific experiences. Participants stated that some of the learning also pushed them out of their comfort zone. Participant G9 stated:

I've met a lot of different people and talk to people now that I would have never come in contact with. It's helped me educationally. I read more, have an interest in places I never heard of, makes me a more interesting person. I believe certain people are chosen to do genealogy and it becomes something you can't not do.

Kramer (2011) stated that genealogy research in some ways brings dead relatives alive as genealogists can feel the presence of their ancestors as they do the research. Participant G2 related a similar experience, saying, "... ancestors will let you know what they want us to know and when. You'll hit brick walls, but it's an almost mystical process-suddenly the information is there that you've been looking for" (Male, 73). Participant G6 also had this experience, stating, "I think there is something spiritual that makes people want to find each other. Some type of divine guidance guides you" (Female, 75).

As participants continued their stories and related to other interview questions, the next phase in the education process emerged, which is collaborative learning. What should be noted is that these phases can happen simultaneously or in any order. In addition, participants did not talk about specific phases, but in the analysis of the data these themes came together in phases.

\subsection{Phase 2: Collaborative Learning}

According to Laal and Laal (2012), collaborative learning "involves groups of learners working together to solve a problem, complete a task, or create a product (p. 451). Through collaborative learning, the learner is often challenged both socially and emotionally because they are able to listen to different perspectives and can contribute their own ideas. In the process of doing family research, the genealogist evolves into a collaborative learner who collaborates with other researchers, librarians, archivists, and information systems to continue the research. Several participants talked about how they had mentors in the beginning of their research. Haley et al. (2015) stated that mentors can help people decide what they want or need to learn. Collaborative learning can begin with only two or three researchers working together, and then evolves into groups of people helping each other. Many participants talked about going to conferences to collaborate with others because you may have information that someone else needs. Garcia-Lorenzo et al. (2008) stated that, as people tell their 
stories, the acquisition of knowledge can start anywhere and people find unique results when they actively collaborate with others. Collaborations have a tendency to increase the individual's awareness.

Collaboration can also happen as a platform for professional development. Beavers (2009) stated that professional development ensures a means for collaboration, support, and training. All participants stated that other people acted as mentors and guides to help in the beginning of their research or when they hit a roadblock. Mentors were described as family members, librarians, historical society employees, or other genealogists. For example, Participant G7 stated, "I worked with someone who was very much into genealogy and was a member of some of the genealogy societies and had gone far back" (Female, 67). Participant G1 stated that "you cannot be afraid to approach people and ask questions." All participants acknowledged that anyone could be a mentor or helper along the way. Participant G9 added, "you can learn from anybody. They always have ways to teach you how to plot land and such, and how people moved from one place to another" (Female, 68).

Genealogists in this study found that collaboration at public libraries, historical societies, or repositories that keep genealogical records was important. All participants stated that they started at the library because of the access to free websites and other services that help genealogists. In addition, participants advised that physically going to the library, historical societies, or other repositories in the county or district where ancestors lived was very important for finding specific information. After going to conferences over time, some participants decided to present their own work at conferences. Collaborative learning can create interest in other topics that can include geography, history, math, and more. Many members had memberships in more than one genealogy group, and some had memberships in local, regional, state, or national groups. Members also used Facebook groups because these groups allow connection with a variety of people who may have different information that could be helpful. Participants also help other people who need help finding specific information.

I also found that the genealogists in this study were some of the most giving people when it comes to sharing. For example, participant G1 stated that one of the members of the Oberlin group introduced Ancestry.com and FamilySearch.com:

[Another member] introduced me to Ancestry.com, Familysearch.org and various forms to assist with organizing my families, which was very helpful. It was not just gathering information and writing; I had to write the citation down. It's important to do this because you can go directly to the source, make comparisons with other data, and save tons of time.

Being able to answer questions for other people who may be stuck is also a part of collaborative learning. For example, participant G4 said:

I do e-mails for the genealogy group and we get questions. We try to research and answer these questions.... Although I was shy before, this [work] makes me get up in front of people. I have something to talk about now and can ask questions when I am around other genealogists. (Female, 62)

In this aspect of collaborative learning, all participants agreed that, once they learned, they also taught others. In fact, there were a variety of ways that were chosen to help others that included theatrical presentations, giving talks at genealogy conferences, and talking about their own genealogy research. Two participants related having publicity about their work. Participant G8 and her ancestry were featured in a National Geographic special:

Yes, my family was featured in a National Geographic project some years ago. They actually sent a professor from Penn State to interview us because they thought it was important to get our story written. The professor who came was actually a Ph.D. candidate and this was some research she needed to complete. (Female, 79) 
By participating in different events, genealogists are able to move their own research forward. Participant G1 stated, “I learned I don't know everything, I don't remember anything, and my perception is different than it was when I first started." Participant G1 also cautioned people who get into genealogy research for the wrong reasons: "I see the people trying to prove they're related to someone famous. If your intent is to find something like you're French or something like that, it won't work."

All participants found that they needed more education in certain areas to enhance what they knew. Learning about history in a specific time period or learning math in order to do land calculations provided another level to their ancestral history. See Table 2. The following is a short list of different academic subjects that participants in this study felt they needed to acquire more information:

Table 2. Different academic subjects that participants in this study felt they needed to acquire more information.

\begin{tabular}{ll}
\hline Academic Discipline & Relationship to Genealogy \\
\hline History & $\begin{array}{l}\text { Civil and other wars, Jim Crow laws, slavery, } \\
\text { Native American and immigrant migration. }\end{array}$ \\
\hline \multirow{2}{*}{ Research } & $\begin{array}{l}\text { New terms, databases, metadata, computer } \\
\text { skills to navigate databases and genealogy sites }\end{array}$ \\
\hline \multirow{3}{*}{ Geography } & Migration of different people at different times \\
& Migration between the north and south \\
& Forms of transportation (e.g., waterways, canals) \\
& Land documents, how land was acquired, who owned the land \\
Math & Map reading, reading topography maps \\
\hline \multirow{3}{*}{ Social Studies (people) } & Calculations and measurement of boundaries \\
& Lynching records \\
& Slavery, birth, death, cemetery records \\
& Pension, military, court house, Chancery Court records \\
Foreign Language & Census records \\
\hline Medical & Handwriting analysis \\
\hline
\end{tabular}

All participants stated that had, it not been for genealogy, they would have had no interested in these topics. As Hershkovitz (2012) stated, genealogy fits the criteria for an academic discipline and is "a research field that juxtaposes many disciplines" (p. 7).

Self-esteem is another area that improves when genealogists are researching their roots. For example, Participant G5, had this to say about how her self-esteem was enhanced:

Thinking that you were docile and you didn't fight doesn't do well for a person of color's ego. But learning that once they came out of slavery they had businesses, boarding houses, and other businesses. Seeing signatures that [said] they [my ancestors] could read and write, and all these wonderful things people of color did. That in as many shades we come in we have that many stories. (Female, 61)

The final way that genealogy and learning intersect (based on this study) is that genealogy becomes a life-long learning endeavor. Although genealogists may stop and start their research over time, they invariably pick up the research again. The learning becomes a process that evolves and engages the genealogist as a learner, hobbyist, and expert.

\subsection{Phase 3: Life-Long Learning}

Hershkovitz and Hardof-Jaffe (2017) stated, "genealogy comprises a very interesting lifelong learning endeavor" (p. 552). I found this statement to be true throughout the interviews conducted. 
All participants stated that, once they started the research, they had to keep doing it because of a passion for the research that could not be quenched unless they continued. They were excited to talk about their own stories. The passion became an obsession and they had to go to places where their ancestors had lived, find minute details to reinforce stories they had been told by family members, and learn languages to get closer to some of their findings. Several members plan vacations around what they want to know. Participant G2 stated: "[This research] has given me a desire to read much more, even fiction based on historical fact. When I go on vacation, I want to go somewhere that I can search historical records tied to ancestors I have found."

As genealogists continue and have more experiences with research, they become more engaged with gathering information and keeping items that might be something other people could use. They also fine-tune what they have already researched:

Most important part was how to piece things together. When I go back, there are things I know, having written information down, I sort of had this vision in my head of what early relatives experienced, but I had this need to find out more and more. (Participant G1: Female, 69)

At some point in the process, genealogists find that they must go beyond books and computers to other resources and they will go to any length to satisfy their natural curiosity: "It's my pastime. It's something I can always go to. I guess I'm just curious. I'll sometimes ask questions ... okay, I'm addicted!" (Participant G3: Male, 73). This natural curiosity also leads to a variety of other opportunities for life-long learning that include conference attendance and presenting information at conferences or other groups. Attending conferences and presenting research is also common in academia.

Becker (2014) states that conference presenting is important for an individual to "achieve intellectual and professional success" (p. 1). Beavers (2009) stated that a benefit of professional development is that it offers opportunities for collaboration, support, and training. Genealogists know what they need to learn and they are active participants in their learning. They follow clues from one place to another. Genealogists build collaborations that last a life-time and some of these relationships are built at conferences (Asbury 2017). Conferences can "keep professionals current in knowledge and competency" (Asbury 2017, p. 49). Conferences promote new learning opportunities and networking with peers, and may provide answers to questions.

All participants shared that conferences were important because of the camaraderie. "Conferences are important because there's so much to learn. I love, love, love the camaraderie with people who love to talk about dead people" (Participant G6: Female, 75). Conferences are also important because there are experts who have more information about very specific things:

At conferences, you're always learning more, you'll always learn something else from other people. You find more info about where to look for information. Records kept by the government or state records. Records you wouldn't think about looking for. You never would think about looking in a certain area. You find out here's a person you can get more information about. (Participant G10: Female, 68)

A variety of genealogy conferences happen locally, regionally, and statewide. The conferences promote a variety of topics addressed by professional genealogists or those who are well-known in the field. For example, Participant G10 explains: "Important? Yes. Conferences can provide more information or enhance the information you already have. There are others who are knowledgeable, who can offer places to look and [talk about] documents that [are] easily made available, I would have never known of."

Two participants mentioned that they took courses in a language other than English to be able to translate some of the documents they found. One was Finnish, the other Old English. For example, when talking about how her ancestors helped ships navigate the area around St. David's Island, Participant G8 explains why she had to learn Old English: "Most of the records I found were written 
in Old English and in order to fully understand them or even read the handwritten records, I had to take a course in Old English to learn how to decipher those records" (Female, 79).

Ballantine (2005) stated that conferences provide an opportunity for networking with peers who can answer questions. Borg (2014) suggested that conferences can show different techniques, teach problem-solving, and provide an opportunity to exchange ideas. Feelings of isolation can also be reduced by going to conferences. For many genealogists, the sense of belonging is important not only as they understand their heritage, but also as they attend other learning opportunities. "Being in a genealogy group, you are with many people who also get obsessed with research. Learning is great!" (Participant G4). Education can change people's perceptions of their families and the world around them. As Participant G9 shared, “You have a certain idea of how life is or should be, but you can't take now [what happens now] or judge what happened in the past by today. I think I have grown past that, [and know] there's nothing to be embarrassed about."

For the genealogists, I interviewed, genealogy research is more than a hobby: It is a lifestyle that continually opens new learning opportunities. "This information can empower you and gives you the motivation to continue" (Participant G10). A final note about life-long learning is that it can help the individual find other ways to be social. For example, as Participant G7 stated: "I've been doing some traveling. I wouldn't have done, I guess I can say I socialize more, at potlucks and conferences. I like to go to a conference where they have different information for three or so days but I would like to see what other people have found ... it's just interesting."

\section{Discussion and Conclusions}

When I first embarked on this research, the topic was intriguing because I saw genealogy as a hobby. I did not know it was multi-faceted and that people engaged in it so obsessively with the help of many others. I found participants very willing to talk about their research, and many personal issues were discussed. I did not use the very personal information because it was not relevant to education. During the course of the interviews, the genealogists I interviewed also taught me.

Adults learn differently than children and this study showed how much many adults value education. For example, the research component of genealogy motivated these adults to interact with study topics that many decided they did not like when they were in high school or college classes. Genealogy provides the spark. Adults are prone to understanding what they need to learn and when. Many start by going on the computer to specific genealogy sites, or reading books on different topics to understand ancestral information more deeply. McLean (2014) stated that often education for adults happens outside of the classroom and this was definitely true for these adults. They were more interested in learning through a variety of means that did not include the formal classroom.

Adults in the study also seemed not to have a specific education plan, but were led into different educational situations because they were looking for specific information that related to their families. Also, many participants in the study were more interested in finding tangible pieces of information that they could hold in their hands, rather than only staying on the computer to find information. These adults were adept at using research skills learned in formal education to figure out what they needed as they pursued their goals (St. Clair 2004; McLean 2014).

Because genealogy is a collaborative process in many respects, genealogists will never have a problem finding information. When they are stuck, there is someone at a conference, a historical society, or somewhere else who may have the information. Loyens et al. (2008) noted that self-directed learning could assist with problem-solving. Many of the participants stated this was exactly what happened for them.

I also think that there is room for genealogists to grow and choose areas where they feel comfortable. Two participants stated that they had acted as different historical characters for special events like Juneteenth. Another participant stated that she used to read novels and create pedigree charts for the characters. Another participant researches a variety of topics and posts his findings on his Facebook page. 
Genealogy research is different for African Americans (and possibly other people of color) because some African Americans (not all) have a history of slavery and all its related issues that happened including lynching records, homes where ancestors lived that are still in existence, and other areas that are not easily found. The African-American participants who found slavery in their lineage also had to confront their own emotions about this issue.

Another interesting aspect to this study was that all participants were older adults, although there are younger members and college students who are members of the group. I think another idea for research is to see how younger people are getting involved in genealogy research and if the intersection between genealogy and education looks different for this group.

The current project was undertaken to answer the research question, "How do genealogists use education to better understand family connections?" The research was also meant to show the connection between genealogy and education. Clearly, education intersects with genealogy in a number of ways. Although most people enter the field for personal knowledge about their family history, the continued effort of researching their roots creates more opportunities to enter into educational pursuits.

Acknowledgments: I would like to thank the members of the Oberlin African-American Genealogy and History Group for participating in the study. I have not received any funding to conduct this research. I have not received any funds to publish in Open Access Journals.

Conflicts of Interest: The author declares no conflict of interest. There were no sponsors connected with this research.

\section{Appendix A}

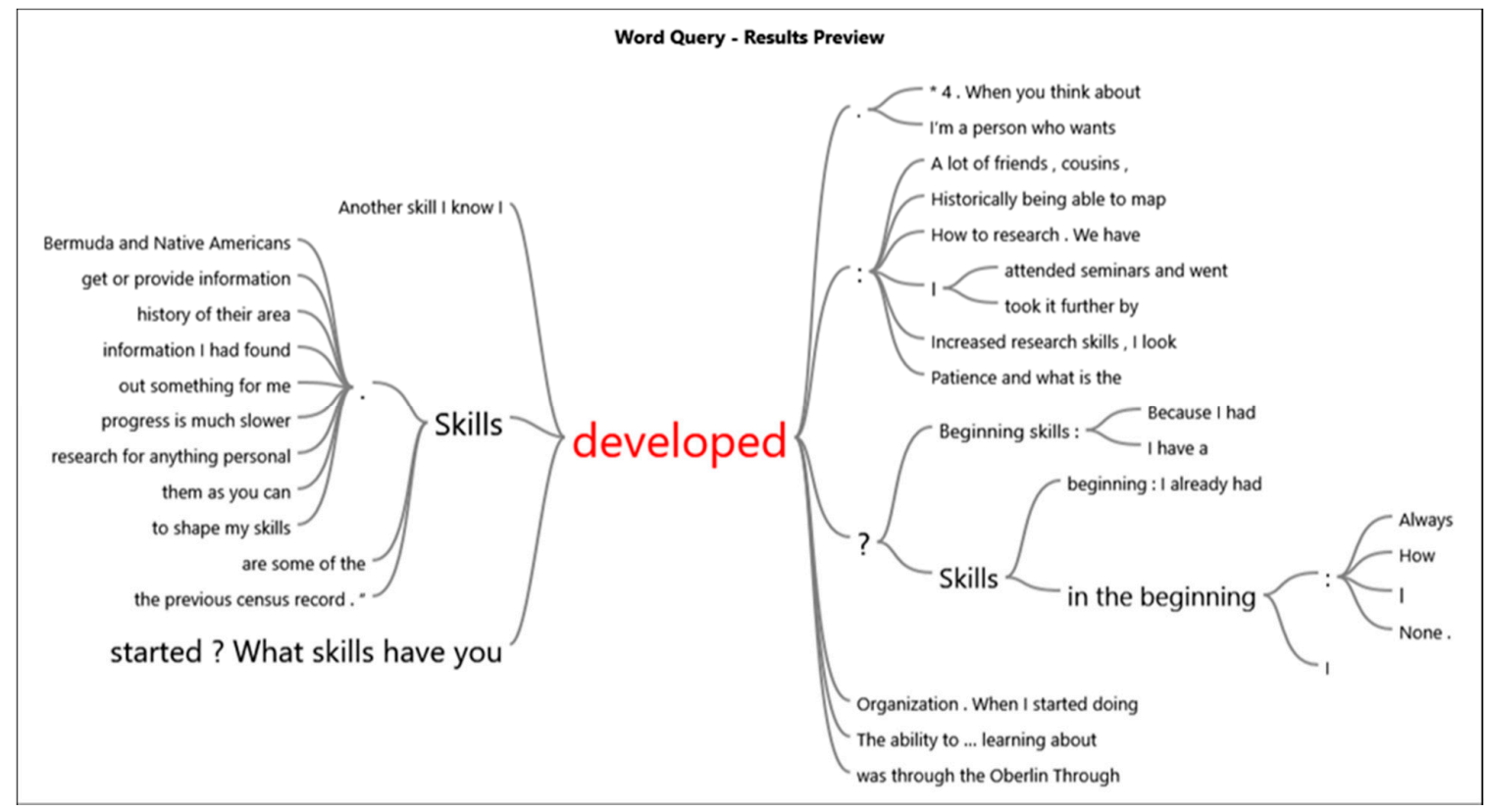

Figure A1. Example: Word tree using the keyword "education."

\section{Appendix B}

Preliminary questions were asked about age, when they started genealogy, the level of education, and gender.

Interview questions:

1. Tell me about your interest in genealogy-how did you get started, why did you start, any interesting tidbits you want to share about the beginning. 
2. What was your process from the beginning? Where did you go, what questions did you ask?

3. What skills did you have when you started? What skills have you developed?

4. When you think about where you were when you started and where you are now, has anything changed for you?

5. What are some of the topics you researched that you knew nothing about when you started? Why were these topics important to you?

6. Has your skill level changed since the beginning? How?

7. What are some of your favorite things you've learned along the way about your family or about other things?

8. Do you have children? Have you taught your children about your roots? OR have you shared this information with other family members or friends?

9. Has the study of genealogy affected you in other areas of your life? If so, please explain.

10. Have you attended any other events relating to genealogy such as conferences or workshops? What were they? Why was this important to do?

11. Now that you've answered all of my questions, are there things that you've thought of that you hadn't realized you learned? Please share those with me.

\section{References}

Asbury, Elizabeth A. 2017. The Importance of Conference Attendance in Developing Research Collaborations. Whitireia Nursing \& Health Journal 24: 59-62.

Ball, Robert. 2016. Visualizing Genealogy through a Family-Centric Perspective. Information Visualization 16: 74-89. [CrossRef]

Ballantine, Linda. 2005. Attending Conferences as a Learning Strategy. CANNT Journal 15: 49-51. [PubMed]

Banville, Michel. 2014. Genealogy and family history. Canadian Issues 6: 59-61.

Beavers, Amy. 2009. Teachers as learners: Implications of adult education for professional development. Journal of College Teaching and Learning 6: 25-30. [CrossRef]

Becker, Lucinda. 2014. Introduction. In Presenting Your Research: Conferences, Symposiums, Poster Presentations and Beyond. London: SAGE Publications, Ltd.

Birchall, Jeff. 2014. Qualitative Inquiry as a Method to Extract Personal Narratives: Approach to Research into Organizational Climate Change Mitigation. The Qualitative Report 19: 1-18.

Borg, Simon. 2014. The Benefits of Attending ELT Conferences. ELT Journal 69: 35-46. [CrossRef]

Bottero, Wendy. 2015. Practising family history: 'Identity' as a category of social practice. British Journal of Sociology 66: 534-56. [CrossRef] [PubMed]

Burr, Sherri. 2016. The Free Blacks of Virginia: A Personal Narrative, A Legal Construct. Journal of Gender, Race and Justice 19. [CrossRef]

Cooper, Karyn A., and Naomi Rebecca Hughes. 2015. Thick Narratives: Mining Implicit, Oblique, and Deeper Understandings in Videotaped Research Data. Qualitative Inquiry 21: 28-35. [CrossRef]

Darby, Paul, and Paul Clough. 2013. Investigating the information-seeking behaviour of genealogists and family historians. Journal of Information Science 39: 73-84. [CrossRef]

Dorsey, Jennifer Hull. 2009. A Documentary History of African-American Freedom: An Introduction to the Race, Slavery and Free Blacks Microfilm Collection. Slavery \& Abolition 30: 545-63. [CrossRef]

Duckworth, Angela L., Christopher Peterson, Michael D. Matthews, and Dennis R. Kelly. 2007. Grit: Perseverance and Passion for Long-Term Goals. Journal of Personality and Social Psychology 92: 1087-101. [CrossRef] [PubMed]

Duff, Wendy M., and Catherine A. Johnson. 2002. Accidentally found on purpose: Information-seeking behaviour of historians in archives. The Library Quarterly 77: 472-96. [CrossRef]

Etikan, Ilker, Sulaiman Abubakar Musa, and Rukayya Sunusi Alkassim. 2016. Comparison of Convenience Sampling and Purposive Sampling. American Journal of Theoretical and Applied Statistics 5: 1-4. [CrossRef]

Freund, Luanne, and Elaine G. Toms. 2016. Interacting with Archival Finding Aids. Journal of the Association for Information Science \& Technology 67: 994-1008. [CrossRef] 
Friday, Kate. 2014. Learning from E-Family History: A Model of Online Family Historian Research Behavior. Information Research 19. Available online: https://files.eric.ed.gov/fulltext/EJ1050454.pdf (accessed on 28 February 2018).

Fulton, Crystal. 2009. The Pleasure Principle: The Power of Positive Affect in Information Seeking. Aslib Proceedings 61: 245-61. [CrossRef]

Fulton, Crystal. 2016. The Genealogist's Information World: Creating Information in the Pursuit of a Hobby. Journal of Multidisciplinary Research 8: 85-100.

Garcia-Lorenzo, Lucia, Sevasti-Melissa Nolas, and Gerard De Zeeuw. 2008. Telling Stories and the Practice of Collaboration. International Journal of Sociology and Social Policy 28: 9-19. [CrossRef]

Gatson, Sarah N. 2003. On Being Amorphous: Autoethnography, Genealogy, and a Multiracial Identity. Qualitative Inquiry 9: 20-48. [CrossRef]

Hackstaff, Karla B. 2009. Turning Points for Aging Genealogists: Claiming Identities and Histories in Time. Qualitative Sociology Review 5: 130-51.

Haley, Karen, Audrey Jaeger, Carrie Hawes, and Jenny Johnson. 2015. Going beyond Conference Registration: Creating Intentional Professional Development for Student Affairs Educators. Journal of Student Affairs Research and Practice 52: 313-26. [CrossRef]

Hershkovitz, Arnon. 2012. A Suggested Taxonomy of Genealogy as a Multidisciplinary Academic Research Field. Journal of Multidisciplinary Research 4: 5-21.

Hershkovitz, Arnon. 2016. Editorial: Genealogy and Family History through Multiple Academic Lenses: An Introduction to the Special Issue. Journal of Multidisciplinary Research 8: 5-10.

Hershkovitz, Arnon, and Sharon Hardof-Jaffe. 2017. Genealogy as a Lifelong Learning Endeavor. Leisure/Loisir 41: 535-60. [CrossRef]

Hickson, Helen. 2016. Becoming a Critical Narrativist: Using Critical Reflection and Narrative Inquiry as Research Methodology. Qualitative Social Work: Research and Practice 15: 380-91. [CrossRef]

Imperato, Pascal James, and Gavin H. Imperato. 2009. The Role of Genealogy and Clinical Family Histories in Documenting Possible Inheritance Patterns for Diabetes Mellitus in the Pre-Insulin Era: Part 1. The Clinical Case of Josephine Imperato. Journal of Community Health 34: 400-18. [CrossRef] [PubMed]

Kramer, Anne-Marie. 2011. Kinship, Affinity and Connectedness: Exploring the Role of Genealogy in Personal Lives. Sociology 45: 379-95. [CrossRef]

Laal, Marjan, and Mozhgan Laal. 2012. Collaborative learning: what is it? Procedia-Social and Behavioral Sciences 31: 491-95. [CrossRef]

Lambert, Ronald D. 2006. Descriptive, Narrative, and Experiential Pathways to Symbolic Ancestors. Mortality 11: 317-35. [CrossRef]

Long, Chris Evin. 2016. Disambiguating the Departed: Using the Genealogist's Tools to Uniquely Identify the Long Dead and Little Known. Library Resources \& Technical Services 60: 236-47. [CrossRef]

Loyens, Sofie M. M., Joshua Magda, and Remy M. J. P. Rikers. 2008. Self-Directed Learning in Problem-Based Learning and its Relationships with Self-Regulated Learning. Educational Psychology Review 20: 411-27. [CrossRef]

McLean, Scott. 2014. Learning on the margins of adult education: Self-help reading about health, relationships, and career success. The Education of Adults 46: 4-22. [CrossRef]

Nerstrom, Norma. 2017. Transformative Learning: Moving Beyond Theory and Practice. International Journal of Adult Vocational Education and Technology (IJAVET) 8: 36-46. [CrossRef]

Olry, Régis, and Duane E. Haines. 2003. Give a Kiss to a Frog and it Will Turn into-A Neuropeptide: The Genealogy of the Bombesin-Like Family. Journal of the History of the Neurosciences 12: 411-12. [CrossRef] [PubMed]

Parham, Angel Adams. 2008. Race, Memory and Family History. Social Identities 14: 13-32. [CrossRef]

Pressly, Thomas J. 2006. The Known World of Free Black Slaveholders: A Research Note on the Scholarship of Carter G. Woodson. The Journal of African American History 91: 81-87. [CrossRef]

QSR International. 2017. What Is Nvivo? Available online: http://www.qsrinternational.com/nvivo/what-isnvivo (accessed on 28 February 2018).

Ray, Nina M., and Gary McCain. 2009. Guiding Tourists to Their Ancestral Homes. International Journal of Culture, Tourism and Hospitality 3: 296-305. [CrossRef] 
Redmann, Gail R. 1993. Archivists and Genealogists: The Trend toward Peaceful Coexistence. Archival Issues 18: 121-32.

Santos, Carla Almeida, and Grace Yan. 2009. Genealogical Tourism: A Phenomenological Examination. Journal of Travel Research 49: 56-77. [CrossRef]

Scodari, Christine. 2016. Recuperating Ethnic Identity through Critical Genealogy. Journal of Multidisciplinary Research 8: 47-62.

Sleeter, Christine. 2008. Critical Family History, Identity, and Historical Memory. Educational Studies: Journal of the American Educational Studies Association 43: 114-24. [CrossRef]

Smith, Amy. 2017. Family Genealogy and Family Communication: Finding Common Ground. Genealogy 1: 6. [CrossRef]

St. Clair, Ralf. 2004. A Beautiful Friendship? The Relationship of Research to Practice in Adult Education. Adult Education Quarterly 54: 224-41. [CrossRef]

Stein, Arlene. 2009. Trauma and Origins: Post-Holocaust Genealogists and the Work of Memory. Qualitative Sociology 32: 293-309. [CrossRef]

Stokas, Ariana Gonzalez. 2015. A Genealogy of Grit: Education in the New Gilded Age. Educational Theory 65: 513-28. [CrossRef]

Yakel, Elizabeth. 2004. Seeking Information, Seeking Connections, Seeking Meaning: Genealogists and Family Historians. Information Research: An International Electronic Journal 10: 205. Available online: https:/ / eric.ed. gov / ?id=EJ1082067 (accessed on 28 February 2018).

Yin, Robert K. 2012. APA Handbook of Research Methods in Psychology, Vol. 2: Research Designs: Quantitative, Qualitative, Neuropsychological, and Biological. Edited by Harris Cooper, Paul M. Camic, Debra L. Long, A. T. Panter, David Ed Rindskopf and Kenneth J. Sher. Washington, DC, USA: American Psychological Association, chp. X; pp. 141-55. 701p.

(c) 2018 by the author. Licensee MDPI, Basel, Switzerland. This article is an open access article distributed under the terms and conditions of the Creative Commons Attribution (CC BY) license (http:/ / creativecommons.org/licenses/by/4.0/). 